\title{
Resilience in action: leading for resilience in response to COVID-19
}

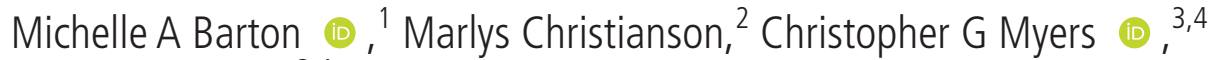 \\ Kathleen Sutcliffe ${ }^{3,4}$
}

Management Department, Bentley University, Waltham, Massachusetts, USA

2Joseph L Rotman School of Management, University of Toronto, Toronto, Ontario, Canada

${ }^{3}$ Carey Business School, Johns Hopkins University, Baltimore, Maryland, USA

${ }^{4}$ School of Medicine, Johns Hopkins University, Baltimore, Maryland, USA

\section{Correspondence to} Dr Michelle A Barton, Bentley University, Waltham, MA 01890 USA; mbarton@bentley.edu

Received 10 April 2020 Accepted 4 May 2020 Published Online First 27 May 2020

Check for updates

(C) Author(s) (or their employer(s)) 2020. No commercial re-use. See rights and permissions. Published by BMJ.

To cite: Barton MA,

Christianson M, Myers CG,

et al. BMJ Leader

2020:4:117-119.

\section{ABSTRACT}

Resilience matters now more than ever in healthcare, with the COVID-19 pandemic putting healthcare providers and systems under unprecedented strain. In popular culture and everyday conversation, resilience is often framed as an individual character trait where some people are better able to cope with and bounce back from adversity than others. Research in the management literature highlights that resilience is more complicated than that - it's not just something you have, it's something you do. Drawing on research on managing unexpected events, coordinating under challenging conditions, and learning in teams, we distill some counter-intuitive findings about resilience into actionable lessons for healthcare leaders.

Given the ongoing COVID-19 crisis, the need for resilience has never been greater. Resilience is the ability to "absorb strain and preserve (or improve) functioning despite the presence of adversity (Sutcliffe and Vogus, p96)."1 However, in the midst of chaos, fear, uncertainty and often completely insufficient resources, the call to 'be resilient' may feel like an impossible demand, especially if you view resilience as something one either has or does not have, a character trait like 'grit' or 'fortitude'. Our own work, however, suggests something different. As we have looked at resilience in emergency rooms, firefighting teams, military units and sports teams, we have come to see resilience not as something you have, but instead as something you do. Nor is it limited to recovery, picking up the pieces after a crisis has occurred. Rather, resilience is an approach to leading and organising that helps teams manage well during adverse conditions. Recognising this is especially important during a drawn-out and constantly changing crisis like the one we currently face. It means that there are steps you can take right now to help your organisation and your teams keep functioning in the midst of adversity.

Enacting resilience is more complicated than just 'digging deep' or 'buckling down', and requires actions that can sometimes seem counterintuitive. Drawing on our own research, as well as other literature in the organisational sciences, we offer leaders three important action steps they can take to build the resilience in action of their employees, teams and organisations.

\section{CREATE PRODUCTIVE DISRUPTIONS}

With chaos unfolding around you, it is tempting to meet urgency with speed, to jump in at the beginning of a shift and not look up until it is over. Our research suggests, however, that this kind of head-down action can lead to dysfunctional momentum. This is the tendency to keep engaging in a set of behaviours without pausing to recalibrate or to re-examine the processes or the changing context. ${ }^{2}$ When situations are volatile, unpredictable and complex, we can get so engrossed in the action that we do not notice small indicators that new problems are emerging or that the situation has changed so that our assumptions no longer hold. ${ }^{3}$ For instance, wildland firefighters can get into trouble if they focus entirely on fighting fires-getting the right people and equipment to the right location, coordinating within and between teams and working to put the fire out-and miss cues that the wind or weather is shifting, which can radically worsen the situation they face.

The solution for dysfunctional momentum is to actually create interruptions. Especially when situations are evolving quickly, it is critical to disrupt the momentum and to create opportunities to check in with one another about what is actually happening as opposed to what we assume is happening. One of the best ways to do this is through huddles, which are short debriefings that provide opportunities for frontline staff and caregivers to stay informed about current events. However, huddles are more than information exchange. They also help staff make sense of work as it is unfolding as people can report concerns and anomalies as they look back on unexpected events and surprises. ${ }^{4}$ Moreover, caregivers can also look forward and report leemers, a term used by naval aviators to describe a gut feeling that something is wrong even though there is no definitive proof. Huddles might be enacted differently during this crisis (ie, they may be virtual instead of face-toface), but they still can improve collective awareness, thereby potentially increasing response time and reducing the potential for failures.

\section{RECONFIGURE, REDEPLOY AND REPURPOSE RESOURCES}

When turmoil replaces our normal daily routine, a tension arises between fighting to maintain normalcy and throwing the rulebook out the window. The most resilient teams, however, do neither. Rather, they take stock of what they have to work with - their routines, roles and resourcesand then reconfigure, redeploy and repurpose. The goal is still to create order from chaos, but to do so by leveraging what you-or others around 
you-already know and do. We have already seen this on an organisational level as distilleries use their resources and manufacturing capabilities to produce hand sanitiser, athletic apparel companies make medical masks and gowns, and hospitals turn emergency rooms and other spaces into COVID-19 intensive care units.

Yet this approach is not limited to physical resources; the daily routines and patterns of interaction among people are also critical resources that can be reconfigured in the face of unprecedented demands. Our routines and operating procedures are not static rulebooks, but in fact are living habits and patterns of interdependent action that can be recreated and revised. ${ }^{6}$ This means we do not have to throw out the old routines when facing a new challenge, because it is still valuable to have some plan (even if it needs to be changed or revised as we go). Instead, we can pull pieces of old routineseither our own or others" — and adapt them to face new task demands as we engage in the 'bricolage' needed to pull together response routines in the face of never-before-seen challenges. For example, our expectations for different roles in the organisation can change, allowing greater flexibility in how we view who does what. Consider the closure of Baltimore's famous B\&O Railroad Museum in 2003 after its roof collapsed onto its collections; this accident effectively eliminated people's normal jobs and ways of working. However, routines and roles were reconfigured to maintain core organisational functions. ${ }^{8}$ In the early days of reconstruction, only steelworkers were allowed onsite. So, curators trained steelworkers to identify artefacts that could be saved and repaired.

Reconfiguration, redeployment and repurposing are also part of the best practices of teams that operate in other adverse conditions. In a study of adventure racing-a teambased endurance sport that involves equal parts physicality and problem-solving-we found that the best teams viewed attention and task engagement as limited resources. 9 They recognised no one could be 'on' at all times and so used roleswitching to make sure the team could keep going, even when individual members needed to 'check out.' They had preassigned backups for key roles and, because they knew they could not always predict when someone might suddenly need a break, they maintained a flexible attitude about changing roles regardless of whose turn (or shift) it was.

\section{ATTEND TO EMOTIONS}

In the face of crisis, it is easy to feel that the only way to avoid becoming overwhelmed by emotions is to ignore or deny them. The problem is, emotions do not disappear simply because we do not acknowledge them. In fact, the opposite is true. However, there is an even bigger problem here than feeling overwhelmed. Negative emotions like grief, fear and anxiety tend to trigger defence mechanisms that undermine our ability to work well with other people. For example, we may look for someone to blame or find ways to withdraw from the situation, becoming more isolated and less involved. As we disconnect from one another and the situation, it becomes nearly impossible to do the work of resilience: communication breaks down; problem-solving and coordination are undermined; and the end result is usually more, not less, adversity.

The work of resilience, therefore, involves directly addressing the emotional implications of adversity. This does not require hours of therapy. Rather, teams can use 'relational pauses', a kind of huddle in which the focus shifts from what a team is doing to how they are feeling and interrelating. ${ }^{10}$ Members are encouraged to share their recent experiences and emotional impact, while others actively listen, demonstrate compassion and acknowledge the validity of their feelings, recognising that each person may have a different reaction to traumatic conditions. This last point is critical because it is easy for teams to ignore or sideline one person who is struggling more than others. Yet, the very process of ignoring someone else's pain can cause fractures in a team that undermine its ability to function (indeed, in adventure racing, we found that the more resilient teams were those that viewed adversity as belonging to the team as a whole, even when only one person was struggling). As members share their experiences, emotional strain is diffused across the group. In addition, a relational pause creates the opportunity to acknowledge and repair any anxiety-triggered dysfunctional interpersonal patterns. Teams that make a habit of taking relational pauses are more likely not only to weather the storm of current crises but also to build critical relational resilience for the future.

\section{LEADING FOR RESILIENCE IN RESPONSE TO COVID-19}

If there is a common thread across these recommendations, it is this: doing resilience involves a great deal of rapid learning. It is about quickly making sense of what is happening-operationally and relationally - and developing an effective response, and then doing that again and again as situations change. Resilient teams learn quickly by taking frequent opportunities to update their understanding (by creating interruptions), by adopting and adapting lessons of past experience (by reconfiguring existing routines, roles and resources), and by building the relational capacity for sharing knowledge and ideas (by attending to emotions). Moreover, in a global pandemic like the one we face with COVID-19, the value of learning is magnified. Teams and leaders around the world are engaged in efforts to update, adapt and reflect on their experience fighting the virus, and can benefit from sharing these lessons with one another and learning vicariously from others' insights (vs just relying on 'trial and error'). ${ }^{11}$ Sharing these experiences (eg, through technology or social media) spreads best practices and builds the collective resilience of the global medical community.

There is much within any crisis that we cannot control. However, reminding ourselves that resilience is about doing more than having is one way to take back some agency and to be the authors of our own stories of how we responded in the face of unprecedented situations. Moreover, when leaders take these actions to 'do resilience' in their teams and organisations - and spread the lessons of these actions to their peers-their stories will highlight how they rose to meet the challenge of the COVID-19 crisis.

\section{Twitter Christopher G Myers @ChrisGMyers}

Contributors All authors contributed to the conceptualisation and writing of the article. MAB is the guarantor and attests that all listed authors meet authorship criteria and that no others meeting the criteria have been omitted.

Funding The authors have not declared a specific grant for this research from any funding agency in the public, commercial or not-for-profit sectors.

Competing interests None declared.

Patient consent for publication Not required.

Provenance and peer review Not commissioned; externally peer reviewed.

This article is made freely available for use in accordance with BMJ's website terms and conditions for the duration of the covid-19 pandemic or until otherwise determined by BMJ. You may use, download and print the article for any lawful, non-commercial purpose (including text and data mining) provided that all copyright notices and trade marks are retained.

\section{ORCID iDs}

Michelle A Barton http://orcid.org/0000-0001-7707-8154 
Christopher G Myers http://orcid.org/0000-0001-7788-8595

\section{REFERENCES}

1 Sutcliffe KM, Vogus TJ. Organizing for resilience. In: Cameron KS, Dutton JE, Quinn RE, eds. Positive organizational scholarship: foundations of a new discipline. San Francisco: Berrett-Koehler, 2003: 94-110.

2 Barton MA, Sutcliffe KM. Overcoming dysfunctional momentum: organizational safety as a social achievement. Human Relations 2009:62:1327-56.

3 Christianson MK. More and less effective updating: the role of trajectory management in making sense again. Adm Sci Q 2019;64:45-86.

4 Goldenhar LM, Brady PW, Sutcliffe KM, et al. Huddling for high reliability and situation awareness. BMJ Qual Saf 2013;22:899-906.

5 Weick KE, Sutcliffe KM. Managing the unexpected. San Francisco: Jossey-Bass, 2001.
6 Dionysiou DD, Tsoukas H. Understanding the (re) creation of routines from within: a symbolic interactionist perspective. Acad Manage Rev 2013;38:181-205.

7 Bresman H. Changing Routines: A Process Model of Vicarious Group Learning in Pharmaceutical R\&D. Acad Manage J 2013;56:35-61.

8 Christianson MK, Farkas MT, Sutcliffe KM, et al. Learning through rare events: Significant interruptions at the Baltimore \& Ohio Railroad Museum. Organ Sci 2009:20:846-60.

9 Barton MA, Sutcliffe KM. Resilience in interaction. Paper presented at Academy of Management Annual Meeting, Atlanta, GA, USA, 2017

10 Barton MA, Kahn WA. Group resilience: the place and meaning of relational pauses. Organ Stud 2019;40:1409-29.

11 Myers CG. Coactive vicarious learning: toward a relational theory of vicarious learning in organizations. Acad Manage Rev 2018;43:610-34. 